\title{
Persistência do plano experimental em ensaios de avaliação de germoplasma elite de feijão
}

\author{
Experimental plan persistence in elite genotypes evaluation for beans assays
}

\author{
Lindolfo Storck ${ }^{I}$ Nerinéia Dalfollo Ribeiro ${ }^{\mathrm{I}}$ Sidinei José Lopes \\ Alberto Cargnelutti Filho ${ }^{\text {II }}$ Melissa Pisaroglo de Carvalho ${ }^{\text {III }}$ \\ Evandro Jost ${ }^{\text {II }}$
}

\section{RESUMO}

A determinação do tamanho de parcela e do número de repetições é importante para a correta avaliação e diferenciação de genótipos. Assim, o planejamento de experimentos pode ser feito utilizando-se os resultados obtidos em ensaios já realizados. O objetivo deste trabalho foi verificar a repetibilidade do índice de heterogeneidade e do plano experimental, numa mesma área experimental com a cultura do feijão, durante sete anos (2000 a 2006). Quatorze ensaios de competição de germoplasma elite de feijão foram conduzidos em Santa Maria, RS, Brasil - em duas épocas de cultivo (safra e safrinha), com diferentes números de entradas (linhagens avançadas e cultivares), no delineamento experimental de blocos ao acaso, com três repetições. Para cada ensaio, foram estimados a média, o coeficiente de variação, o coeficiente de correlação intraclasse e o índice de heterogeneidade do rendimento de grãos de feijão. Também foram estimadas as diferenças verdadeiras entre duas médias de tratamentos pelo método de Hatheway para diferentes valores do índice de heterogeneidade, número de repetições e tamanho de parcela. A freqüência dos valores do índice de heterogeneidade entre 0,2 e 0,7 foi de $71 \%$, evidenciando que o plano experimental, com base nos resultados de experimentos anteriores, tem validade em $71 \%$ dos casos. Não parece haver predominância de valores do índice de heterogeneidade em função da época de cultivo - safra ou safrinha, ou do tipo de experimento - VCU ou Cultivares, mostrando boa repetibilidade ou persistência no decorrer dos anos.

Palavras-chave: tamanho de parcela, número de repetições, repetibilidade, melhoramento.

\section{ABSTRACT}

The determination of the plot size and the repetition number is important to the correct evaluation and differentiation of genotypes. The experimental planning can be made using previous results in already conducted assays. The objective of this work is to verify the repeatability of the heterogeneity index and the experimental plan, in the same experimental area with beans culture, during seven years (2000 to 2006). Fourteen competitive assays of elite genotype beans had been tested in Santa Maria, State of Rio Grande do Sul, Brazil - in two growing seasons (normal and off season crops), with different treat numbers (advanced lines and variety). The experiment was carried out in a randomized complete block design with three replications. For each assay, the mean, variation coefficient, intraclass correlation coefficient and heterogeneity index of the grain yield of beans were determined. Also the true differences between two means of treatments by Hatheway methods, using for different values of the heterogeneity index, repetition number had been estimated together with the plot size. The frequency of the heterogeneity index between 0.2 and 0.7 was $71 \%$, evidencing that the experimental plan, on the basis of the results of previous experiments, has validity in $71 \%$ of the cases. It does not seem to have $b$ predominance in function of the growing seasons - normal and late season crops, or of the type of experiment - VCU or variety, showing a good repeatability or persistence in elapsing of the years.

Key words: plot size, replications number, repetibilidade, crop breeding.

\section{INTRODUÇÃO}

No planejamento de experimentos, a determinação do tamanho de parcela e do número de repetições, com base nos resultados de ensaios conduzidos em anos anteriores, é importante para a

\footnotetext{
IDepartamento de Fitotecnia, Centro de Ciências Rurais (CCR), Universidade Federal de Santa Maria (UFSM), 97105-900, Santa Maria, RS, Brasil. E-mail: lindolfo@smail.ufsm.br.*Autor para correspondência.

IIDepartamento de Ciências Exatas, Faculdade de Ciências Agrárias e Veterinárias (FCAV), Universidade Estadual Paulista (UNESP). Via de Acesso Prof. Paulo Donato Castellane, s/nº, 14884-900, Jaboticabal, SP, Brasil.

IIIPrograma de Pós-graduação em Agronomia, UFSM, Santa Maria, RS, Brasil.
} 
correta avaliação e diferenciação de genótipos. O plano experimental é dependente do índice de heterogeneidade do rendimento de grãos (b) e do coeficiente de variação (CV) obtidos numa área experimental. Segundo LIN \& BINNS (1986), quando b for menor do que 0,2 , os experimentos devem ser planejados no sentido de aumentar o número de repetições de parcelas menores e, quando b for maior do que 0,7 , os experimentos devem ser estruturados com parcelas maiores e menor número de repetições. Também, quando o valor de b estiver entre 0,2 e 0,7, deve-se procurar uma combinação adequada entre número de repetições e tamanho de parcela para se obter a precisão necessária e, nesse caso, que represente economia de mão-de-obra e de recursos financeiros.

Nos ensaios de uniformidade, a produtividade da cultura é avaliada em pequenas parcelas (unidades básicas) para a simulação de parcelas de diferentes tamanhos. A relação entre os diferentes tamanhos de parcelas (X) e as variâncias reduzidas para uma unidade básica (VUx) foi estudada, inicialmente, por SMITH (1938). Esse autor propôs uma relação empírica $\mathrm{VUx}=\mathrm{V} / \mathrm{X}^{\mathrm{b}}$, em que b é o índice de heterogeneidade do rendimento de grãos, sendo que o tamanho da parcela é obtido, graficamente, como o ponto de máxima curvatura da relação. Posteriormente, métodos algébricos foram empregados para estimar o ponto de máxima curvatura da relação entre o tamanho da parcela (X) com a variância ou com o coeficiente de variação (MEIER \& LESSMAN, 1971; THOMAS, 1974).

Considerando que a execução de um ensaio de uniformidade no ano anterior para a estimativa do tamanho de parcela, para uma determinada cultura e área experimental, envolve mais tempo e recursos financeiros, KOCH \& RIGNEY (1951) propuseram um método para a estimativa de b com base nos resultados de experimentos executados em delineamentos como o látice, ou em parcelas subdivididas. No caso de experimentos no delineamento em blocos ao acaso, com parcelas subdivididas, as parcelas podem assumir o tamanho do bloco, da parcela principal e da subparcela. Quando comparada com os ensaios de uniformidade, que permitem a simulação de parcelas com maior variação de tamanho, essa metodologia é menos adequada para a estimação do índice de heterogeneidade, porque usa menor número de pares de dados. Além disso, aplicações desses delineamentos, na experimentação, não são freqüentes.

A possibilidade de se estimar o índice de heterogeneidade da área experimental, a partir da estimativa da correlação intraclasse de ensaios no delineamento blocos ao acaso, utilizando apenas dois tamanhos de parcelas (bloco e parcela), foi apresentada por LIN \& BINNS (1984). Apesar da estimativa não ser tão precisa, o procedimento é bastante atrativo devido ao grande número de experimentos executados no delineamento blocos ao acaso. Também é importante porque possibilita o acompanhamento da evolução da heterogeneidade da área experimental, em função da cultura e do manejo, entre outros. Isso permite que o tamanho da parcela ou o número de repetições sejam alterados em experimentos posteriores. Aplicações dessa metodologia, para as culturas da soja, cevada e aveia, foram usadas para estudar a repetibilidade das estimativas de b num período de quatro anos (LIN et al., 1996). Posteriormente, ALVES \& SERAPHIN (2004) obtiveram estimativas de b para diferentes delineamentos experimentais.

A obtenção das estimativas de b e CV, para um dado tamanho de parcela, permite o planejamento de experimentos com combinações de tamanho de parcela (não muito diferente do usado nos experimentos) e do número de repetições, usando a metodologia de HATHEWAY (1961). Sendo assim, o objetivo deste trabalho foi verificar a repetibilidade do índice de heterogeneidade e do plano experimental numa mesma área experimental com feijão durante o período de sete anos.

\section{MATERIAL E MÉTODOS}

Quatorze ensaios de competição de germoplasma elite de feijão (linhagens avançadas e cultivares), foram conduzidos em área experimental do Departamento de Fitotecnia da Universidade Federal de Santa Maria (UFSM), Santa Maria, RS. O município está localizado na região fisiográfica da depressão central do Estado do Rio Grande do Sul, entre as coordenadas geográficas de $29^{\circ} 45^{\prime}$ de latitude sul, $53^{\circ} 42^{\prime}$ de longitude a oeste de Greenwich, e a uma altitude de $95 \mathrm{~m}$.

Os ensaios foram executados durante os anos de 2000 a 2006, em duas épocas de cultivo: safra com semeadura em setembro ou outubro, e safrinha com semeadura em janeiro ou fevereiro, em solo Brunizem Hidromórfico pertencente à unidade de mapeamento Santa Maria (EMBRAPA, 1999). Em todos os ensaios, a adubação foi realizada de acordo com análise química do solo, segundo as Recomendações de Adubação e Calagem para os Estados do Rio Grande do Sul e Santa Catarina (COMISSÃO DE FERTILIDADE DO SOLO-RS/SC, 1995).

O delineamento experimental de blocos ao acaso, com três repetições, foi utilizado nos ensaios de Valor de Cultivo e Uso (VCU) e de cultivares registradas para o cultivo no Estado do Rio Grande do Sul (CULT), com diferentes números de entradas em cada ano (Tabela 1). As parcelas foram compostas de quatro fileiras de quatro metros de comprimento, espaçadas de $0,50 \mathrm{~m}$, e a área útil da parcela consistiu das duas 
Tabela 1 - Ano de colheita, época de cultiyo (época), tipo de ensaio (tipo), número de genótipos (ng), rendimento de grãos de feijão (Rend, $\mathrm{kg} \mathrm{ha}^{-1}$ ), correlação intraclasse ( $\rho$ ), índice de heterogeneidade (b) e coeficiente de variação (CV, em \%) da área experimental de feijão. Santa Maria-RS, UFSM, 2006

\begin{tabular}{|c|c|c|c|c|c|c|c|}
\hline Ano & Éроса & Tipo* & ng & Rend & $\rho$ & b & $\mathrm{CV}$ \\
\hline 2000 & Safra & VCU & 20 & 3005 & 0,2580 & 0,4074 & 11,96 \\
\hline 2001 & Safra & VCU & 24 & 1545 & 0,1651 & 0,5066 & 23,29 \\
\hline 2001 & Safrinha & CULT & 16 & 916 & 0,1943 & 0,5077 & 22,56 \\
\hline 2002 & Safra & VCU & 14 & 1248 & 0,2084 & 0,5033 & 24,42 \\
\hline 2002 & Safra & CULT & 19 & 2393 & 0,8413 & 0,0553 & 18,89 \\
\hline 2002 & Safrinha & CULT & 19 & 713 & 0,1948 & 0,4888 & 24,55 \\
\hline 2003 & Safra & VCU & 18 & 494 & 0,1167 & 0,6218 & 31,06 \\
\hline 2003 & Safrinha & CULT & 19 & 253 & 0,2057 & 0,4742 & 34,68 \\
\hline 2004 & Safra & VCU & 26 & 1595 & 0,2238 & 0,4211 & 22,94 \\
\hline 2004 & Safra & VCU & 16 & 2313 & 0,0256 & 0,8829 & 13,42 \\
\hline 2004 & Safra & CULT & 19 & 1986 & 0,0465 & 0,7936 & 12,12 \\
\hline 2004 & Safrinha & CULT & 19 & 897 & 0,1797 & 0,5098 & 20,09 \\
\hline 2005 & Safra & CULT & 18 & 1969 & 0,5008 & 0,2206 & 8,97 \\
\hline 2006 & Safra & CULT & 21 & 2351 & 0,0369 & 0,8183 & 17,29 \\
\hline Média & - & - & 19 & 1548 & 0,2284 & 0,5151 & 20,44 \\
\hline
\end{tabular}

* VCU = ensaio de valor de cultivo e uso; CULT = ensaio de cultivares registradas.

fileiras centrais, nas quais se desprezaram $0,50 \mathrm{~m}$ das extremidades, totalizando $3,0 \mathrm{~m}^{2}$ por unidade experimental.

De cada experimento, foram usados a média do rendimento de grãos com $13 \%$ de umidade, o quadrado médio de erro (QME), o quadrado médio de bloco (QMB), o coeficiente de variação do erro experimental (CV) e o número de genótipos por bloco (ng). Foi estimado o coeficiente de correlação intraclasse $(\rho)$ usando a expressão:

$$
\rho=\sigma_{b}^{2} /\left(\sigma^{2}+\sigma_{b}^{2}\right)
$$

em que $\sigma^{2}$ é o QME e $\sigma_{b}^{2}=(\mathrm{QMB}-\mathrm{QME}) / \mathrm{ng}$. O índice de heterogeneidade (b) de cada experimento foi estimado

pela expressão $b=1-\frac{\log [n g-(n g-1)(1-\not)]}{\log (n g)}$

(LIN \& BINNS, 1984).

A diferença verdadeira entre duas médias de tratamentos, expressas em percentagem da média (d), foi estimada através do método de HATHEWAY (1961), cuja fórmula é

$$
d=\sqrt{2\left(t_{1}+t_{2}\right)^{2} C V^{2} / r X^{b}}
$$

em que $r$ é o número de repetições requerido para detectar diferenças de $d$ unidades; CV é a estimativa do coeficiente de variação em percentagem para uma unidade básica; $\mathrm{t}_{1}$ é o valor da tabela de t para testes de significância (bilateral a 5\%); $t_{2}$ é o valor da tabela de $t$ correspondente a um erro de 2(1-P), em que $\mathrm{P}$ é a probabilidade de se obter resultados significativos; $\mathrm{X}$ é o tamanho das parcelas planejadas; e b é a estimativa do índice de heterogeneidade. No caso, foram considerados os valores de b igual a 0,2 , média dos valores de b obtidos dos experimentos $(0,5151)$ e 0,7 ; $C V=20,44 \%$; $x$ igual a 4, 8 e $16 \mathrm{~m}^{2}$; e r igual a 3, 4 e 5 repetições; no caso de um experimento com 20 genótipos.

\section{RESULTADOS E DISCUSSÃO}

Dos quatorze experimentos avaliados entre os anos de 2000 a 2006, numa mesma área experimental, em apenas um caso o índice de heterogeneidade indicou o uso de parcelas menores e um maior número de repetições - devido ao valor de b ser menor do que 0,2 - e, em três casos, indicou o uso de parcelas maiores e um menor número de repetições, pois b foi maior do que 0,7 , conforme é recomendado por LIN \& BINNS (1986) (Tabela 1). Na maioria dos casos, o pesquisador deverá planejar uma combinação adequada entre o número de repetições e o tamanho de parcela, pois valores de b entre 0,2 e 0,7 foram obtidos. Sendo assim, o plano experimental, com base nos resultados de experimentos anteriores, tem validade em $71 \%$ dos casos. Essa persistência é bem mais alta do que os $50 \%$ verificado por LIN et al. (1996). Observa-se, também, que não deve existir influência nos valores de b pela simples repetição do experimento no mesmo local, mas sim pelas interações da heterogeneidade da área com o clima e/ou os genótipos usados nos experimentos.

Ciência Rural, v.37, n.6, nov-dez, 2007. 
O tamanho da parcela não pode variar muito, para mais ou para menos do que foi usado nos experimentos em que foram estimados os valores de b, por isso o método de HATHEWAY (1961) deve ser usado com certas limitações no dimensionamento. Considerando os valores de b iguais a 0,2; 0,5151 (média dos b) e 0,7, com CV=20,44\%; $x$ igual a 4, 8 e 16m²; e r igual a 3, 4, e 5 repetições; no caso de um experimento com 20 genótipos, pode-se obter as precisões (d) apresentadas na tabela 2. O aumento do número de repetições é muito mais eficiente para o aumento da precisão (redução do valor de d) quando o valor de b é menor e quando as parcelas são menores. Nesse caso, o pesquisador deve optar por planejar um experimento considerando as restrições de cada caso. Assim, podem-se considerar restrições quanto às dimensões da área disponível, quantidade de sementes, disponibilidade de recursos financeiros ou humanos e quanto à precisão desejada. A possibilidade de usar parcelas menores e maior número de repetições pela substituição do uso de bordaduras em experimentos de feijão (RIBEIRO et al., 2001) é adequada na maioria dos casos.

Não parece haver predominância de valores do índice de heterogeneidade em função da época de cultivo (safra ou safrinha) ou do tipo de experimento (VCU ou Cultivares), evidenciando boa repetibilidade ou persistência no decorrer dos anos. Esse fato é muito importante para validar o planejamento dos próximos experimentos, em função das informações disponibilizadas em anos anteriores. Também, se o

Tabela 2 - Diferença verdadeira entre duas médias de tratamento (d), expressa em percentagem da média, estimada pelo método de Hatheway, para diferentes valores de b $(0,2$; 0,5151 e, 0,7), com $C V=20,44 \%$; com 4, 8 e $16 \mathrm{~m}^{2}$ por parcela; e r igual a 3, 4 e 5 repetições, no caso de um experimento com 20 genótipos. Santa Maria-RS, UFSM, 2006.

\begin{tabular}{lccc}
\hline \multirow{2}{*}{$\begin{array}{l}\text { Número de } \\
\text { repetições }\end{array}$} & \multicolumn{3}{c}{ Tamanho de parcela $\left(\mathrm{m}^{2}\right)$} \\
\cline { 2 - 3 } & \multicolumn{2}{c}{4} & 16 \\
\hline & \multicolumn{2}{c}{$\mathrm{b}=0,2 ; \mathrm{CV}=20,44$} \\
3 & 41,8 & 40,0 & 36,4 \\
4 & 35,8 & 33,5 & 31,2 \\
5 & 31,9 & 29,8 & 27,8 \\
& $\mathrm{~b}=0,5151 ; \mathrm{CV}=20,44$ & \\
3 & 33,6 & 28,1 & 23,5 \\
4 & 28,8 & 24,1 & 20,2 \\
5 & 25,6 & 21,5 & 17,9 \\
& $\mathrm{~b}=0,7 ; \mathrm{CV}=20,44$ & \\
3 & 29,5 & 23,2 & 18,2 \\
4 & 25,4 & 19,9 & 15,6 \\
5 & 22,6 & 17,7 & 13,9 \\
\hline
\end{tabular}

pesquisador resolver alterar o plano experimental, utilizando menor número de repetições e parcelas maiores, ou vice-versa, o mesmo estará procedendo adequadamente em $71 \%$ dos casos.

Outro resultado importante (Tabela 3) é a ausência de correlação linear entre a média do rendimento de grãos e a estimativa de $b(r=-0,02)$, que é determinante da magnitude da estimativa da precisão (d). Com isso, o plano experimental - relacionado aos valores de b-não deve variar diretamente em função dos anos e das épocas de cultivo, que, devido às diferentes condições ambientais, afetam a média do rendimento de grãos (Tabela 1).

Por outro lado, quanto maior o rendimento de grãos, menor será o CV $(\mathrm{r}=-0,83)$ e maior será a precisão (menor d). Este resultado é importante para os casos de experimentos de alta produtividade (ou CV baixo), para o controle de qualidade ou eliminação de experimentos com resultados impróprios. Nos métodos de comparação múltipla de médias de tratamentos, é importante a magnitude da variância e do número de repetições, independentemente da média geral. Desse modo, se um experimento com o uso de altas tecnologias (ambiente favorável) resultar em médias altas para todos os tratamentos, implicando a redução do CV devido ao aumento da média geral, isto não implica melhor qualidade do experimento, porque a variância das médias estimadas não é reduzida. Um experimento tem boa qualidade quando pequenas diferenças entre médias de tratamentos são significativas (d baixo). Dessa forma, o critério de usar apenas o CV para a eliminação de experimentos de baixa precisão pode ser equivocada.

\section{CONCLUSÕES}

A freqüência dos valores do índice de heterogeneidade entre 0,2 e 0,7 é igual a 71\%, evidenciando que o plano experimental, com base nos

Tabela 3 - Coeficiente de correlação linear de Pearson em relação ao rendimento de grãos de feijão (Rẹnd, $\mathrm{kg} \mathrm{ha}^{-1}$ ), coeficiente de correlação intraclasse $(\rho)$, índice de heterogeneidade (b) e coeficiente de variação (CV, em \%) da área experimental de feijão. Santa Maria-RS, UFSM, 2006.

\begin{tabular}{clll}
\hline & Rend & $\rho$ & $\mathrm{b}$ \\
\hline$\rho$ & $0,23 \mathrm{~ns}$ & - & - \\
$\mathrm{b}$ & $-0,02 \mathrm{~ns}$ & $-0,91^{*}$ & - \\
$\mathrm{CV}$ & $-0,83^{*}$ & $-0,14 \mathrm{~ns}$ & $-0,03 \mathrm{~ns}$ \\
\hline
\end{tabular}

* Significativo a 5\% de probabilidade, pelo teste t, com 12 graus de liberdade; ns = não-significativo. 
resultados de experimentos anteriores, tem validade em $71 \%$ dos casos.

Não há predominância de valores da precisão e do índice de heterogeneidade relacionados com a época de cultivo - safra ou safrinha - ou com o tipo de experimento - VCU ou Cultivares - mostrando boa repetibilidade ou persistência no decorrer dos anos.

\section{AGRADECIMENTOS}

À Coordenação de Aperfeiçoamento de Pessoal de Nível Superior (CAPES), pela concessão de bolsa à pesquisadora Melissa Pisaroglo de Carvalho.

\section{REFERÊNCIAS}

ALVES, S.M.F.; SERAPHIN, J.C. Coeficiente de heterogeneidade do solo e tamanho de parcela. Pesquisa Agropecuária Brasileira, v.39, p.105-111, 2004.

COMISSÃO DE FERTILIDADE DO SOLO-RS/SC. Recomendações de adubação e calagem para o Estado do Rio Grande do Sul e Santa Catarina. 3.ed. Passo Fundo: SBCC-Núcleo Regional Sul, EMBRAPA/CNPT, 1995. 223p.

EMBRAPA. Centro Nacional de Pesquisa de Solos (Rio de Janeiro, RJ). Sistema Brasileiro de classificação de solos. Brasília: Embrapa-SPI, 1999. 412p.
HATHEWAY, W.H. Convenient plot size. Agronomy Journal, v.53, p.279-280, 1961.

KOCH, E.J.; RIGNEY, J.A. A method of estimating optimum plot size from experimental date. Agronomy Journal, v.43, p.17-21, 1951.

LIN, C.S.; BINNS, M.R. Working rules for determining the plot size and numbers of plots per block in field experiments. Journal of Agricultural Science, v.103, p.11-15, 1984.

LIN, C.S.; BINNS, M.R. Relative efficiency of two randomized block designs having different plot size and numbers of replications and of plots per block. Agronomy Journal, v.78, p.531-534, 1986

LIN, C.S. et al. Persistence of a field heterogeneity index. Canadian Journal of Plant Science, v.76, p.245-250, 1996.

MEIER, V.D.; LESSMAN, K.J. Estimation of optimum field plot shape and size for testing yied in Crambe abyssinica hordnt. Crop Science, v.11, n.5, p.648-650, 1971.

RIBEIRO, N.D. et al. Bordadura em ensaios de competição de genótipos de feijoeiro relacionados à precisão experimental. Ciência Rural, v.31, n.1, p.13-17, 2001.

SMITH, H.F. An empirical law describing heterogeneity in the yields of agricultural crops. Journal Agricultural Science, v.28, p.1-23, 1938.

THOMAS, H.L. Relationship between plot size and plot variance. Agricultural Research Journal of Kerala, v.12, n.2, p.178-189, 1974 . 